\title{
Armadilha à francesa: homens sem profissão
}

\author{
A French-like trap: men without profession
}

\author{
Lidiane Soares Rodrigues \\ lidianesr@uol.com.br \\ Doutora \\ Universidade de São Paulo \\ Av. Liberdade, 532 - Liberdade \\ 01502-001 - São Paulo - SP \\ Brasil
}

\section{Resumo}

O presente artigo caracteriza o trabalho das missões francesas de fundação da Faculdade de Filosofia, Letras e Ciências Humanas da Universidade de São Paulo (FFCL-USP) - especialmente, o papel desempenhado por Fernand Braudel. Entre as atribuições da missão de que era parte constava a seleção de alunos para dar prosseguimento às atividades institucionais em fase posterior à estruturação empreendida pelos franceses. É possível, por meio do exame minucioso dos escolhidos surpreender a atenção do missionário aos potenciais conflitos locais, concentrados no novo constructo institucional. Outrossim, torna possível auscultar desdobramentos de seus princípios de seleção, assinalando o intercâmbio entre a recém fundada FFLC-USP e a tradicional Faculdade de Direito do largo São Francisco (FD). Para tanto, são apresentados perfil social, motivações ligadas ao trabalho historiográfico e às práticas de ensino e pesquisa dos escolhidos, em particular, Eduardo D'Oliveira França.

\section{Palavras-chave}

Fernand Braudel; Conhecimento histórico; História das instituições.

\begin{abstract}
This article examines the work of the French missions for the inauguration of the School of Philosophy, Linguistics and Human Sciences of the University of São Paulo (FFCL-USP) - in particular, the role played by Fernand Braudel. Among the tasks of his mission, one finds the selection of students to continue the activities at a later stage to the institutional structuring undertaken by the French. It is possible, through a careful exam of the selected students, to be struck by the missionary's surprising attention to potential local conflicts, concentrated as they were on the new institutional construct. Moreover, it is possible to investigate developments of the principles of selection, which signalize to the exchange between the newly-founded FFLC-USP and the traditional Largo do São Francisco School of Law (FD). To this end, we present the social profile and the motivations related to the work and historiographical practices of teaching and research of the selected students, in particular, Eduardo D'Oliveira França.
\end{abstract}

\section{Keywords}

Fernand Braudel; Historical knowledge; History of institutions.

Enviado em: 16:/11/2012

Aprovado em: 21/2/2013 
A inteligibilidade da historiografia universitária pressupõe a caracterização de seus mentores, docentes, clientelas e, sobretudo, das motivações levadas pelos mesmos, para as aulas, teses, pesquisas e toda sorte de atividades acadêmicas. Nesse sentido, o presente trabalho recupera o projeto de fundação da Faculdade de Filosofia, Letras e Ciências Humanas da Universidade de São Paulo (doravante, FFCL-USP), em 1934; a importação de professores estrangeiros e as tarefas delegadas a eles; bem como as estratégias de que se valeu, em particular, Fernand Braudel, para a execução delas, frente à cátedra de história da civilização. A adoção desse procedimento permite assinalar alguns nexos entre o novo constructo institucional e a antiga Faculdade de Direito do Largo São Francisco (doravante, FD), bem como entre as motivações da elite mentora e dos primeiros inscritos nos cursos da FFCL-USP, em especial os da $5^{a}$ seção de história e geografia. A relevância desses nexos, para os quais nem sempre a bibliografia especializada atenta, é posta à prova com o exame de textos programáticos. A leitura dos mesmos, à luz do quadro esboçado, possibilita explicitar a conversão de impasses não historiográficos em procedimentos historiográficos. Como se trata de apresentar resultados de uma pesquisa mais ampla, um caso exemplar é selecionado para tanto: Eduardo D'Oliveira França e a defesa da "história-problema".

\section{Tarefas de um missionário}

[...] o acaso - sempre benéfico - favoreceu a secção de história, dando-lhe, como estudantes, alguns juristas (BRADUEL 1935).

As elites mentoras da criação da FFCL-USP equiparam-na com docentes oriundos de outros países. A nova faculdade compunha-se de três seções: Filosofia, Ciências e Letras. Dentro da segunda, havia cinco subseções, sendo a quinta, História e Geografia, composta de cinco cadeiras. Dentre elas, duas eram ocupadas por franceses: "geografia física e humana" e "história da civilização". Émile Coornaert inaugura esta cadeira no seu primeiro ano letivo. Entre 1935 e 1937, Fernand Braudel esteve na direção dela. Jean Gagé o substitui em 1938. Estas mudanças remontam às três missões francesas de fundação da instituição (PEIXOTO 1991; CAPELATO; PRADO 1989).

A primeira delas caracteriza-se por ser uma "delegação transitória", cujos membros não tinham a intenção de permanecer mais que os meses necessários para inauguração dos cursos. A segunda missão tem como "figura típica", o "jovem professor efetivo, professor de um liceu de província", que têm "estudantes a formar e a continuar acompanhando" (PETITJEAN 1996, p. 268). No cumprimento desta tarefa, Fernand Braudel escreveu "O ensino de história e suas diretrizes" para o primeiro Anuário da FFCL-USP.

O diagnóstico a respeito do corpo discente propicia o entendimento de seus critérios de seleção dos futuros quadros. Para ele, "falta aos estudantes paulistas [...] uma cultura geral de base, sem a qual é difícil progredir com rapidez." No entanto, "o acaso - sempre benéfico - favoreceu a secção de 
história, dando-lhe como estudantes, alguns juristas". E "não é de espantar que conhecedores das fortes disciplinas do direito, esses estudantes se tenham regular e automaticamente posto à frente dos seus companheiros" (BRAUDEL 1935, p. 125). A quais alunos se referia Fernand Braudel? A Caio Prado Jr., Roberto Sergio de Paiva Meira, José Egydio Bandeira de Mello, Ubaldo da Costa Leite, Eurípedes Simões de Paula, Antônio de Paula Assis, Eduardo D’Oliveira França, Astrogildo Rodrigues de Mello, Affonso Antônio Rocco - alunos da Faculdade de Direito do Largo São Francisco. ${ }^{1} \mathrm{O}$ historiador, face esta "ligação fortuita, eficiente para o recrutamento de estudantes de valor", defendia: é "necessário que a ponhamos ao abrigo de uma ruptura tão fortuita como o seu estabelecimento" (BRAUDEL 1935, p. 125). Noutros termos: o acaso nos favoreceu, mas para evitar uma virada da sorte, melhor ter estratégia. Foi o que ele fez.

À passagem de Braudel a Gagé, em 1938, sucedeu a federalização, em 1939, implicando a divisão da cátedra de história da civilização em: antiga e medieval/ moderna e contemporânea. Eurípedes Simões de Paula assume as tarefas didáticas e científicas da primeira, e escolhe como assistente Eduardo D'Oliveira França; a cargo de Gagé, ficam as da segunda, e ele escolhe como assistente, Olga Pantaleão. A federalização não implicou contratações compatíveis com as divisões a que deu origem, e apenas com o decreto estadual de 1942, o desdobramento foi tornado oficial, as contratações correspondentes encaminhadas, e os doutoramentos, obrigatórios para assistentes, regulamentados e acelerados. Neste ano, doutora-se Eurípedes Simões de Paula, com a tese "O comércio varegue e o Grão Principado de Keiv", sob direção de Gagé. Mas ele não havia se desligado do exército. Nem a FD, da oposição a Vargas (DULLES 1984). E ambos se uniam no sentimento de nacionalismo e antifascismo, a animar os corações paulistas entre 19421945. Convocado, em 1943, para o serviço ativo do Exército, como oficial da reserva, o jurista-historiador, agora pracinha, apresenta-se, segue com 10 Escalão da Força Expedicionária Brasileira (FEB) que desembarcou em Nápoles. Eduardo D'Oliveira França passa a reger a cátedra de antiga/ medieval, e nomeia Pedro Moacyr Campos, licenciado na 5a seção em 1940 e ainda aluno da FD, como assistente. França divide suas energias entre a substituição de Eurípedes, o que inclui aulas de história greco-romana, na seção de Letras, e a elaboração de sua tese de doutoramento. No segundo semestre de 1947, Fernand Braudel volta ao Brasil, e, como catedrático desta mesma cadeira, retira a assistente de Gagé e nomeia França. A estada de Braudel no Brasil, desta feita, é mais breve que a primeira, porém não menos decisiva. Indica Émile Léonard, para assumir o posto no ano seguinte, e este mantém França como assistente. Com a partida de Léonard, em 1949, França se torna regente. Em 1951, defende sua livre-docência, "Portugal na época da restauração", com a qual conquista a cátedra

\footnotetext{
${ }^{1}$ Os nomes dos alunos matriculados (e ouvintes) nos cursos da FFCL-USP podem ser encontrados nos Anuários da FFCL-USP. Buscando, um por um, os alunos da $5^{a}$ seção que tiveram aulas com Braudel, nos arquivos digitalizados da Associação de ex-alunos da FD (www.arcadas.org.br) chega-se ao elenco acima, bem como ao ano em que concluíram o bacharelado.
} 
no ano seguinte. A cátedra de história Americana também seria conquistada, no ano da breve visita de Braudel, por um dos jovens que havia chamado sua atenção: Astrogildo Rodrigues de Mello. ${ }^{2}$

Quando Braudel der sua lição inaugural em 1950, no Collège de France, "As posições/responsabilidades da história em 1950", são, no Brasil: Eurípedes Simões de Paula, catedrático de história antiga e medieval; Astrogildo Rodrigues de Mello, catedrático de história americana; Eduardo D'Oliveira França, preparando-se para ser catedrático de história moderna e contemporânea. A morfologia resulta, parcialmente, da artimanha que transformou o "acaso" em cálculo: Braudel extraiu rendimento da conversão da formação prévia desses alunos "adiantados", auxiliou seus escolhidos, orientou seus sucessores franceses, e manteve-se atentíssimo ao significado das escolhas para os brasileiros. Longe de ser aleatória, a operação seletiva em jogo denota senso para as demandas da elite e aproveitamento máximo dos recursos humanos num mínimo de tempo disponível. Daí selecionar quadros cujo capital cultural era mais elevado do que a média; além de afinados com as causas paulistanas, esposadas pelos mentores do constructo institucional. ${ }^{3}$ Com efeito, o deslocamento dos mesmos, para a FFCL-USP, em que eram alunos atípicos, não se desvencilha da "Revolução constitucionalista de 1932", vivida do ângulo da FD, em que eram alunos típicos, como se mostra a seguir. Dentre os quatro mosqueteiros em tela - Eurípedes, Astrogildo, Pedro Moacyr e França - o foco se dirige lentamente ao último, notadamente o D'Artagnan desta configuração. ${ }^{4}$

\section{Questão de honra: fazer história}

[...] tu estás agora aí, não mais a ensinar história, mas a viver história (COSTA 1944).

Os anos formação dos juristas que instigaram Braudel foram marcados pela derrota militar de 1932 (HILTON 1982; BORGES 1997; MOTA; SANTOS 2010), pela incorporação da FD à USP (MARTINS; BARBUY 1998), pela reforma das Arcadas, em 1935 (GROLA 2012). São dimensões que concorreram com o "acaso" para incliná-los a escolher a 5 a seção da nascente FFCL. ${ }^{5}$

Até serem atingidos pelas transformações sociais e políticas que caracterizam os anos 1920-1945 (MICELI 2001), os cursos jurídicos eram espaço de socialização dos destinados "à advocacia, ao Ministério Público, à política, à diplomacia" uma "pepineira da elite política", que se arvorava produzindo também filosofia,

\footnotetext{
2 Os dados biográficos de Eurípedes Simões de Paula foram retirados de PAULA (1983); os de Eduardo D'Oliveira França, do processo 46.1.207.8.7.

${ }^{3}$ Para contornar a dificuldade de não ter alunos regularmente matriculados, nos primeiros anos da FFCL-USP, Fernando de Azevedo criou a possibilidade de "comissionamento": professores primários, com dispensa de tarefas didáticas e sem perda dos rendimentos, poderiam bacharelar-se nos cursos ofertados (LIMONGI 2001, p. 187-218). À luz do perfil do recrutamento traçado pelo sociólogo, os juristas são localizados no leque de oportunidades profissionais ligadas ao valor do diploma, da FD e da FFCL, a seguir.

${ }^{4}$ Devo a sugestão a Fernando Antônio Novais. Ele e Rogerio Forastieri dividiram comigo memórias que guardam de França e Ihes sou grata por isso. O termo "configuração" é empregado no mesmo sentido de ELIAS 2001.

${ }^{5}$ Naturalmente, a boutade com o "acaso" dialoga com "O acaso como resíduo de motivação na historiografia". O encaminhamento aqui dado gostaria de ser uma alternativa à "antítese preguiçosa entre necessidade e acaso" (KOSELLECK 2006, p. 147).
} 
literatura, poesia, ficção, artes, pensamento social (VENANCIO FILHO 1977, p. 273). No "celeiro" dos "aprendizes do poder" (VENANCIO FILHO 1977), os jovens tomavam parte nas causas "liberais" que mobilizaram o cenário nacional: Abolição da escravidão, Proclamação da República, cisão do Partido Republicano Paulista (PRP) e fundação do Partido Democrático (PD) (PRADO 1986). E, a partir de 1930, oposição a Vargas, momentos áureos dela: pela constituição em 1932, pela redemocratização, em 1945 (DULLES 1984). Decerto, as reformas no ensino jurídico, sobretudo, a partir de 1879, e o novo recrutamento social, a partir dos anos 1920, modificaram as condições que levaram Sergio Adorno defender que a formação dos bacharéis "não residiu no processo de ensino-aprendizagem" e nos conteúdos escolares em stricto sensu (ADORNO 1988, p. 26). Porém, do ponto de vista da incorporação de disposições típicas o ambiente extracurricular continuou decisivo. A história, a ser feita, vivida e simbolizada, era como o sangue correndo nas veias de alunos e professores.

Na tarde de 09 de julho de 1932, cerca de 1500 pessoas encontraram-se em frente à FD, clamando pela insurreição. As Arcadas se transformaram em "uma movimentada, às vezes confusa, sede de recrutamento" da batalha pela Constituição (DULLES 1984, p. 71). Não é difícil imaginar os futuros alunos de Braudel eletrizados com a grandeza da missão. A "Campanha pela Autonomia e Constitucionalização", mais conhecida por sua fase militar, "Revolução Constitucionalista", queria recuperar o que fora perdido em 1930: a centralidade de São Paulo na federação, proclamando a necessidade de Constituição para o Brasil. A "Frente Única pela Constituição", formada em fevereiro de 1932, reunia antigos inimigos, do PRP e do PD contra o governo federal, que havia nomeado um interventor alheio à política do Estado, João Alberto Lins de Barros (SANTOS; MOTA 2010, p. 15-26). Eram motes da campanha, entre outros, a exaltação da paulistanidade, a recuperação da figura do bandeirante - figura mobilizada para forjar o patriotismo paulista, espécie de "símbolo da lealdade do estado à nação". Apelos que são também os temas diletos dos historiadores de então, Taunay, Alcântara Machado e Alfredo Ellis Jr. - que, na qualidade de "membros das elites imbuídos do 'orgulho paulista', ao estudar a própria ascendência, procuraram reforçar sua legitimidade estabelecendo laços entre essas elites e os heróis do passado bandeirante, legitimando-as" (BORGES 1997, p. 72; FERREIRA 2002).

Derrotados, os paulistas não sossegariam. Entre as medidas compensatórias, tem destaque a fundação da FFCL e da USP (CARDOSO 1982; LIMONGI 2001). E se sua criação é parte das investidas paulistas contra o novo arranjo político do governo Vargas, esta bandeira em comum concorreu para a integração da FD no experimento universitário. Quando ocorre a fundação da USP, a FD se encontra "combalida e cheia de incertezas embora com pleno impulso de recuperação, traduzido pela própria reforma de seu prédio" (MARTINS; BARBUY 1998, p. 180). Para que ela pudesse integrar a USP, foi necessário que passasse da União ao Estado - incluindo aí, prédio, instalações, e todo seu patrimônio. Esse trâmite, a centralidade no projeto universitário, atribuída à $F F C L$, a derrota de 1932 talvez conferissem à escola um sentimento de estar sendo ultrapassada. E logo se verificou que a "integração foi de âmbito puramente formal", fazendo- 
-se forte a "resistência das faculdades tradicionais, na qual se destacava a faculdade de Direito" (VENANCIO FILHO 1977, p. 307). O problema da costura institucional teve implicações para as "ditas 'faculdades tradicionais'", posto que sua incorporação padeceu da ausência de compromissos prévios, solidamente alicerçados (LIMONGI 2001, p. 185).

Em 1935, eram demolidas as Arcadas: para serem reerguidas. A reforma das instalações, ao seu modo, confessava o valor atribuído à história de São Paulo como história do Brasil. Alcântara Machado, jurista, historiador e mentor da reforma, por meio dela, oferece bom testemunho das concepções historiográficas difundidas na vivência da FD. No conjunto, a ornamentação arquitetônica e os vitrais podem ser entendidos como "alegoria de uma história do Brasil animada e fundamentada pelo Direito e por valores universais": Força, Temperança, Filosofia, Justiça (MARTINS; BARBUY 1998, p. 190). A demolição do antigo edifício intentava reforçar a "secular missão de formar grandes homens responsáveis por conduzir a nação", aliando a modernidade de se adaptar a novas necessidades e a tradição, expressa numa farta ornamentação que recupera o passado institucional (GROLA 2012, p. 90).

O apreço por "história" não se desvencilha da pretensão de envolvimento nos "destinos históricos" do país, a partir de São Paulo, para os professores e estudantes da FD. Outrossim, não foram poucos os historiadores que passaram pela instituição - Perdigão Malheiro, Washington Luís, Alfredo Ellis Jr., Alcântara Machado, Caio Prado Jr., Brasil Bandecchi, Francisco Martins, Raul de Andrade, Ernani da Silva Bruno, Célio Debes (MARTINS; BARBUY 1998, p. 195) - e, no itinerário dos historiadores cuja prática se realizou em período anterior ao molde universitário, há uma indiferenciação entre história como acontecimento e história como área de conhecimento. Do mesmo modo, no Largo São Francisco, o corpo discente e docente tinha suas energias mobilizadas para a "história", indiferenciadamente: estudos históricos e possibilidades de intervenção nos rumos históricos eram face de uma mesma moeda. E, na base de uma ou outra direção, a componente típica do grupo dominante, cuja homogeneidade era socialmente reforçada pela vivência escolar. O ethos dos paulistas de quatrocentos anos forja a autoimagem dos mesmos, "como se fossem os agentes imprescindíveis do processo histórico. É como se o tempo deles fosse coincidente com o tempo político institucional. Confirmam, pois, a ideia tão difundida sobre o grupo dominante como sendo aquele que faz a história" (TRIGO 2001, p. 25).

Na concepção extracurricular de história do Largo formaram-se Eurípedes, França, Astrogildo, Pedro Moacyr. Os corações desses jovens se encontraram na luta, na derrota e na busca de alternativas a ela. Eles, como a elite paulista, ligaram seus destinos aos investimentos compensatórios da derrota militar. Aquela, idealizando a USP; eles, tornando-se alunos da unidade dela que concentrava as pulsões daquela derrota: a FFCL. Eis a marca indelével na vida da "geração de 1932 [que] descobriu [um] compromisso nascido da decepção injusta - vencer em outro plano para reaver o bem perdido. A liberdade havia de voltar, choramingávamos de raiva" e amargavam em seus verdes os anos: 
Eurípedes tinha 20, enquanto seu calouro, França, 17 anos. "E foi assim que vimos nascer, nos escombros do sonho político, a Universidade de São Paulo, a oferecer horizontes para a busca da redenção dos espíritos machucados pelo desgosto da derrota". As esperanças de 1932 eram "amor contrariado: vira teimosia" (FRANÇA 1994, p. 260).

\section{Herói vencido: ensino de história}

[...] a fecundidade da poesia épica portuguesa [...] reclama uma explicação surgindo assim como flor de decadência. A ternura pelo passado é um sintoma (FRANÇA 1997).

O itinerário dos juristas-historiadores expressa possibilidades abertas pela segmentação das elites paulistanas na diferenciação de suas instituições de ensino, bem como o sentido de 1932 em 1934. Eles se uniram ao projeto de implantação do quartel general desta nova trincheira, a universidade, motivados por ideais similares aos que os estimularam a aderir à "Revolução de 1932". Se "em última análise, a campanha pela criação da universidade está ligada à luta pelo controle do setor educacional tomado em seu conjunto" (LIMONGI 2001, p. 179), eles tomaram parte nela com perfis sociais desviantes da clientela plebeia, característica da FFCL-USP, mas estimulados pelos mesmos ideais, e dotados de capital cultural e social próximo ao dos fundadores dela: estratégia braudeliana, veleidades paulistanas.

Nascido em Queluz, interior de São Paulo, em 1915, Eduardo D'Oliveira França foi aluno do Ginásio Nogueira da Gama, entre 1927 e 1931. Ingressou na FD em 1932 e nela se formou em 1936: "eu era calouro de Direito" (e de Eurípedes, vale mencionar), "quando chegou a revolução dos paulistas contra a ditadura. Aquele clima apaixonado intoxicou-me irreversivelmente deste amor à liberdade que, como um vício, nunca mais me deixou". No mesmo ano do conflito, "para fazer render o tempo que desperdiçava, matriculei-me na Escola Normal da Praça" - onde seu pai havia estudado. "1932" possibilitou-Ihe dar vazão a disposições sociais carreadas da educação familiar e tanto a luta quanto a derrota foram constitutivas de seu estilo. Em suas palavras:

a trincheira é uma grande escola: aprende-se não só a enfrentar o perigo sem esquivas, mas sobretudo a valorizar o companheirismo, a apurar o valor dos outros e a amar o chão da trincheira que nos protege. Setor Sul, Batalhão Fernão Sales, motivo de exaltação para cada um de nós, 'pátrias-amadas' recrutados a granel (FRANÇA 1994, p. 260).

À "causa paulista" (CAPELATO 1982) ele se entregou, "em 24, como em 30 e 32, embora travestidas de argumentos, eram [as minhas] posições essencialmente afetivas, quando mal começava a pensar politicamente" (FRANÇA 1976, p. XIV). Ainda em 1933 matriculou-se Instituto de Educação (IE-USP), obra dos "novos educadores" também envolvidos no projeto de criação da FFCL-USP, tendo Fernando de Azevedo à frente. Em 1935 tornou-se, novamente, ao se matricular no curso de história e geografia, na FFCL-USP, 
calouro de Eurípedes - cuja influência por tal escolha, reconhece juntamente com a de Astrogildo Rodrigues de Mello (FRANÇA 1994a, p. 151). Em 1936, por concurso, é nomeado professor adjunto do Grupo Escolar Alfredo Bresser, da capital, permanecendo em comissão na FFCL-USP. No ano seguinte, prestou concurso para cadeira de assistente de Educação, e, aprovado, ingressou na Escola Normal Pe. Anchieta. Além dessas atividades, também se dedicou ao magistério, em escolas particulares tradicionais como o Colégio Rio Branco, o Colégio Bandeirantes, o Ginásio Saldanha da Gama.

França adotou a docência como profissão, talvez por influência familiar: sua mãe era professora e o levava para o trabalho na escola, seu pai, além de cuidar do sítio onde moravam, também lecionava. Comparando-se os itinerários prévios à conquista de cátedra, de Eurípedes e França, conclui-se que o primeiro foi beneficiado pela escolha de Braudel, pois estava adiantado no curso de história e geografia, em um ano. França, se já tinha abraçado a carreira docente estava em desvantagem, para assumir o posto, mas formava com o veterano a dupla selecionada pelo historiador francês. De todo modo, o percurso acima descrito sugere que suas atenções profissionais se dirigem primordialmente ao ensino, sendo possível supor que antes de ser professor de história, seu desejo fosse ser, simplesmente, professor. Não se encontra registro algum de passagem dele por outros espaços profissionais, e, paralelamente às duas graduações, ele se dirige a instituições de formação pedagógica, terminando por "optar pela história e geografia depois de muito hesitar abandonando o Instituto de Educação onde ajudara a fundar o Grêmio 2 de Agosto" (FRANÇA 1994, p. 261).

Nos anos iniciais da FFCL-USP, "a carreira científica se apresentava [...] como canal de mobilidade social ascendente" (LIMONGI 2001, p. 204). Esta modalidade de recrutamento caracterizou o estilo de trabalho da cadeira de Sociologia I, por exemplo. A organização do trabalho em equipe, a eliminação das marcas aristocráticas e da aquisição doméstica do capital cultural, em prol da cientificização propiciada pelo aprendizado escolar, o interesse por temas de relevância política, aliado a tomada de distância de apelos partidários são traços definidores da sociologia praticada por Florestan Fernandes e seu grupo, especialmente entre 1952 e 1969 (ARRUDA 2001). Por outro lado, a instituição também ofereceu "recurso para os que, ameaçados [de descenso] pelas transformações sociais em curso, podiam ser abrigados pela universidade" (LIMONGI 2001, p. 204). ${ }^{6}$ Embora a prioridade da FFCL fosse a formação de professores, tal propósito, dependente de um plano articulado de reforma do ensino nos três níveis, não vingou, senão nos anos 1950, com a expansão do ensino médio. Na prática, a seleção de "vocações científicas" acabou se impondo, em função tanto do estrangulamento do mercado para professores do médio quanto da partida dos franceses. Por isso, foi rápida e numerosa a ascensão de recém- formados aos postos de docência da própria instituição (LIMONGI 2001, p. 218). É neste conjunto que França se localiza.

\footnotetext{
${ }^{6}$ Há uma excepcionalidade na área de Sociologia. Enquanto os setores de Filosofia, História e Geografia, Letras (e a incipiente Crítica Literária) concentrava alunos egressos da FD e de camadas em descenso social, aqueles que se dirigiam à Sociologia tinham origem mais modesta e o diploma conquistado exclusivamente na nova faculdade. O paralelo e o contraste podem ser encontrados em: RODRIGUES 2012.
} 
Entre os papeis desempenhados por ele, um dos mais destacados consistia no encaminhamento da aula como ritual e na impostação performática de sua autoridade. Certa vez, confessou: "ninguém resistia ao fascínio da iniciação" promovida pelos professores franceses (FRANÇA 1994, p. 261). Queria ele repetir o feito com seus alunos? Decerto. E realizá-lo pressupunha estabelecer com nitidez a diferença de papéis por meio do exercício da autoridade professoral - notável, no controle do tempo dos alunos por meio do seu. Assim, cultivou idiossincrasias por meio de práticas não modernas, entre as quais merece menção o notável acordo de trabalho estabelecido no primeiro dia de aula. Ele "(costumava) atrasar no mínimo 30 minutos". Explicava que "a pontualidade britânica é a característica dos medíocres. Professor que nada tem a dar oferece a seus alunos sua pontualidade". O atraso é mantido como prerrogativa professoral, os alunos deveriam chegar pontualmente, de modo que ele fosse "o último a entrar nesta sala. Depois que eu entrar ninguém entra, não adianta pedir licença, estão proibidos de entrar atrasados". Ademais, "perguntas somente depois que eu terminar minha exposição" (NOVAIS 2004, p. 54). No discurso da cerimônia que Ihe conferia o título de professor emérito, acertava os ponteiros: "[confesso que] não éra[mos] modelo[s] de simpatia, convencido[s] de que estáva[mos] predestinado[s] a mudar os rumos do ensino e da cultura" (FRANÇA 1994, p. 263). Era aquela indiferenciação entre estudar história e fazê-la, convertida então em fazê-la, ensinando. Entretanto, professor França ensinava história?

"Ensinar a saber ñ é ensinar o q sabe" - é assertiva encontrada entre as anotações preparatórias de suas aulas, e sintetiza suas diretivas pedagógicas. Nesses manuscritos, pode-se ler, em letra miúda e caprichada, levemente inclinada à direita, dando sinais de cultivo da elegância da caligrafia, o título de uma aula: A Aula de história: introspecção da aula - aula sobre aula. As anotações consistem num conjunto de orientações para futuros professores organizarem suas aulas, estabelecerem com seus alunos uma relação propícia ao ensino tanto do conteúdo disciplinar quanto das técnicas de produção desse conteúdo, o que requer a imposição de autoridade, pressuposta na assimetria dos papéis. Na "aula como um todo", deve o professor atentar para o aluno, a matéria, e o tempo - calculando sua distribuição para, "fazer render": "tempo útil, tempo de amaciar e repetições" (FRANÇA s/d). Nas lições sobre "ser professor", afirmar que ser historiador e ser professor sejam dois atributos da formação, para França, é correto, mas insatisfatório: são articuladas de tal modo que exigiriam uma só palavra. É tangível nesta aula um ensino de ofício, e, como na corporação, ensinar o ofício não é ensinar o que sabe, senão ensinar o saber de fazer: fazer aula/alunos/docentes - fazer história/historiografia.

Para tanto, ele propunha dois tipos de seminário: os seminários de documentos e os seminários-aula. Trata-se de herança dos missionários franceses: a) a concepção subjacente à prática em tela - de que a formação do bom professor de história e do historiador são indissociáveis (BRAUDEL 1935); b) a proposta da prática de seminários, vista como antídoto ao problema da falta de "cultura geral" diagnosticado por Braudel (GAGÉ 1938). Segundo França, os 
seminários de documentos tinham por meta ensinar os alunos a produzir história por meio da combinação das informações extraídas das fontes, ultrapassando a simplória ordenação cronológica, para alcançar um "tratamento verdadeiramente historiográfico dos elementos levantados na leitura das fontes", o que só é possível "mediante treino adequado que permita a superação do empirismo por um esforço de sistematização através do ensino concreto e prático das próprias técnicas de trabalho". Para se chegar à redação, em pelo menos duas fases podem ser divididos os procedimentos descritos pelo professor. Uma é "preparatória" e visa à "inteligência" do material. Ela consiste na distribuição de três ou quatro fontes contemporâneas a respeito do mesmo assunto; exame da validez das informações; cotejo, entre os textos e com outras fontes, para identificação de convergências ou conflitos de dados. Criando uma situação de escolha para o aprendiz, "entre dados de vária procedência", combate-se "a aceitação ingênua dos testemunhos". Outra fase consiste na definição do problema que os fará retornar aos textos "para colherem os elementos que Ihes permitam comprovar a correção das respostas que tenham encontrado". Trata-se de desenvolver a capacidade de mobilizar os dados para a elaboração de "explicações válidas", tomando distância da reprodução das informações; bem como, de tornar perceptível que tais explicações variam conforme a ênfase dada aos "aspectos: o político, o cultural, o econômico, o social". Somente depois de definido o problema, elabora-se um plano de redação com itens e "previsão dos passos a serem utilizados e das conclusões finais". Por fim, a terceira etapa consiste na redação, estando proibidas transcrições, "para evitar-se a tendência a fugir à expressão própria". No interior dessas regras, tem o aluno liberdade quanto ao tema e quanto à ênfase, e a redação final deve ser composta assim: apresentação da problemática, argumentação, com base empírica, e conclusão, com explicação. Em suma: "não se pretende o aprendizado dos fatos de que tratam os textos, mas da técnica da utilização deles"; porque, afinal, "ensinar a saber não é ensinar o que sabe". Testemunhando a dificuldade na execução de seu plano, teima: se para nada servir, "terá sido útil ensinar os alunos a escrever história, o que geral e infelizmente não sabem [...] E não sabem, porque nunca se Ihes ensinou, dentro do sistema de passiva repetição de aulas mal anotadas contra o qual é preciso reagir" (FRANÇA 1965, p. 273-276). O seminário de documentos acentua a dimensão de pesquisa em detrimento da docência e o seminário aula faz o inverso - articulados, documentam a concepção de que o bom professor de história é também historiador. Nos seminários-aula, os alunos deveriam dar uma aula a respeito de um tema, relativo aos conteúdos do ensino secundário. Compartilhava das preocupações de Gagé - os "alunos aprenderão a ensinar a história somente quando eles mesmos, sob fiscalização do professor, procederem a exercícios de aprendizagem" (GAGÉ 1938, p. 32).

Tanto no seminário-texto quanto no seminário-aula destaca-se o empenho em defender uma concepção segundo a qual o ofício é pesquisa e docência. Conduta notável pelo fato de orientar a boa aula de modo similar a seu modelo de excelência em historiografia: "História problema", sinônimo de Lucien Febvre. Ressalte-se aí: história não se faz só com documentos e não se resume 
a acontecimentos. Foi o que se observou nas "três fases da redação", e é também o que se encontra nos manuscritos de aula: "a reflexão como ponto de partida inquietação - as leituras devem sugerir a problemática associada ao campo de interesse - ter o que procurar - para provar" (FRANÇA s/d). A deliberação a respeito da articulação entre os papeis de professor/historiador orientou suas próprias práticas. Desse modo, não se surpreendem disposições não historiográficas em tomadas de posição historiográficas apenas em suas aulas.

\section{Questão de método: vencer derrota}

Como mulher, a glória mais difícil havia de ser a mais apetecida (FRANÇA 1997).

Quando leu Teoria geral da história do Brasil, de José Honório Rodrigues e sentiu arrepios ao se deparar com a assertiva segundo a qual "a história serve de ganha-pão, aos bibliotecários, arquivistas, professores de história", Eduardo D'Oliveira França estava à flor da pele com questões de método e dificuldades para o prosseguimento de sua carreira. Comece-se pela primeira fonte de inquietações, mais elevada e menos clandestina que a segunda: para que esta possa iluminar aquela.

França concluía a tese de cátedra, "Portugal na época da Restauração", ao resenhar a obra de José Honório Rodrigues. Ela pode ser lida, por isso, como um programa, que documenta, por um lado, o acanhado cenário da historiografia paulistana e as dificuldades dos primeiros catedráticos brasileiros na $5^{a}$ seção, e, por outro, os esforços de França para fazer valer suas concepções historiográficas. É exclusivamente desse ângulo, em função dos limites impostos pela economia deste artigo, que nos propomos a apresentar o que escreveu, sob o pretexto de comentar a obra de Jose Honório Rodrigues. Por esta razão, vale recortar uma proposição que estabelecerá uma divisa duradoura entre os herdeiros e rivais desse programa, a saber: o "problema" ou a "documentação" como norteador da pesquisa historiográfica.

França ironiza: o "historiador precisa provar, e para provar usa os documentos. Feita a prova surge a certeza. Muito simples. Como num processo judicial". À luz do itinerário social exposto, poderia ele se satisfazer em ser "mero trabalhador do Direito"? Não. E ele converte a sina do descenso social em status, por meio da nobilitação viril do métier de historiador. Contra a "tirania da prova material subjugando a inteligência" e contra o "historiador eunuco no harém dos fatos", produzido e pressuposto por ela, França evoca a autoridade de Febvre: não há história, há historiadores, são eles que constroem fatos, o que não significa dizer que os inventem. Como estuda fatos, a "ginástica do historiador é caçá-los em documentos lídimos". E toda a metodologia "gira", assim "em torno do documento - viveiro de fatos [...] plano Langlois-Seignobos com clarões de filosofia". Em tom enérgico, assevera: "é terrorismo metodológico a escravização aos documentos"; eles "são apenas material para inteligência, quando o historiador não é somente comentarista de documentos. A justaposição 
de peças anatômicas não compõe o homem: é preciso um sopro de vida". Não se prova "fatos que realmente aconteceram", "por estarem documentados": "provam-se hipóteses: explicações à espera de comprovação. E o que provoca a hipótese é a intuição dos fatos; não os documentos lidos" (FRANÇA 1951, p. 113-137).

Seguindo a lição de "atirar carga ao mar para não soçobrar no oceano dos fatos" (FRANÇA 1951, p. 123), encaminhe-se uma hipótese, então. Como ficou patente, o cenário profissional em tela corresponde à dinâmica das "zonas de incerteza", tanto com relação às "condições de acesso quanto às condições de exercício" da atividade. Nestes casos, os rumos dependem precipuamente das credenciais que os agentes em disputa lograrem impor e elas tendem a se constituir por meio da "definição da profissão mais favorável ao que eles próprios são", ou conseguiram ser (BOURDIEU 2001, p. 193). O "sopro de vida" ardente com que França encarna os "combates pela história" liga-se à história e historiografia indiferenciadas, que aprendeu na socialização da FD; aos três anos de convívio com Braudel, à passagem pelo IE-USP, ao acompanhamento da revista dos Annales, ao retorno de Braudel, à visita de Lucien Febvre em 1948, às conversas com os mosqueteiros, às demandas de seus alunos, indiscutivelmente. No entanto, a "intuição" atina as dificuldades que teve de enfrentar para conceber suas duas teses, a de doutorado e a de cátedra - face ao (re)conhecimento tanto da modernidade dos Annales quanto da tradição do métier. As dificuldades condicionaram tais tomadas de posição pari passu a conversão nobilitadora do trabalho por meio da qual logrou compensar simbolicamente a sina social e manter a noblesse que o tempo roubava a galope, da vida e dos historiadores. É esta peculiar combinação que lhe imprime caráter inconfundível, e que singulariza a primeira geração de catedráticos no setor de história, em relação a setores cujo recrutamento social foi oposto ao dela, como no setor de Sociologia I (ARRUDA 2001). Documente-se esta hipótese.

Tenho acompanhado as pesquisas realizadas antes de minha partida
para a Itália, e verificando ao voltar os trabalhos realizados na minha
ausência, julgo-os satisfatórios, e embora tenha verificado que as
pesquisas realizadas foram embaraçadas por deficiências de fontes e de
bibliografia, crônicas em nosso meio e agravadas pela interrupção das
relações comerciais com a Europa, julgo tratar-se de trabalho digno de
ser discutido (PAULA 1945).

Assim Eurípedes justificava a defesa de doutorado de França ao voltar da guerra e apressar seus amigos às titulações, em 1945.7 Para França, o resultado esteve longe dos seus próprios parâmetros de aprovação: "[o doutorado veio] em meio ao atropelo das aulas e em regime de tempo parcial. Então, nada de bolsas. Desacatei $O$ poder real em Portugal e a banca foi conivente comigo" (FRANÇA 1994, p. 262). A enfática defesa daquela modalidade de trabalho segundo a qual tem prioridade o problema em relação à documentação é 
tributária das limitadas possibilidades com que desenvolveu sua tese, e que o obrigaram a atinar para dimensões que possivelmente não defendesse com tanta garra, não fossem as condições adversas que contornou para lograr realizá-la. É essa sofreguidão que se encontra numa singela anotação de aula: "o doc. ñ governa a pesquisa" (FRANÇA s/d). Decerto, como ele próprio sentencia, a "história dos sentimentos é mais importante do que geralmente reconhecem os historiadores mais severos" (FRANÇA 1997, p. 218). Se a abundância de alguns recursos for prejudicial à maturidade com relação a eles, a escassez o tornou mais sensível ao uso racionalizado da documentação. A tese com a qual conquista a cátedra foi elaborada "sem consulta e pesquisa em biblioteca e assuntos europeus, nomeadamente portugueses" (NOVAIS 1997, p. 9). Insatisfeito, e, como se ao diminuir a si próprio pudesse engrandecer o trabalho que empreendeu, apresenta-a:

quem, entre nós sem poder sair do Brasil, limitado pela carência de recursos documentais e bibliográficos, se dedicar à indagação da história geral da civilização, quase tudo o que pode aspirar, como contribuição à historiografia, é concorrer para o aperfeiçoamento dos métodos de elaboração histórica. A historiografia não progride apenas pela descoberta de novos fatos ou de novas relações entre eles. Há uma terceira frente: alargamento das possibilidades de compreensão, pela aplicação de novas técnicas de aproveitamento dos dados existentes. Consolo de pobre quer trabalhar (FRANÇA 1997, p. 11).

O uso e abuso da enumeração de agradecidos eram incomuns nas teses das primeiras décadas da faculdade. Daí o relevo quando ocorrem agradecimentos nominais. Nada casual aqui. Com efeito, a certa altura do capítulo "As ideias políticas da restauração", França surpreende com um "precioso manuscrito da Biblioteca de Paris", cuja transcrição desproporcional com relação ao conjunto de citações documentais obriga ele próprio a se justificar: "alongamos a citação para divulgar mais o precioso códice", logo ele, que condenava a paráfrase por intimidar a "expressão pessoal". E informa: "[o documento] foi-nos comunicado graças à gentileza dos profs. Fernand Braudel e Vitorino de Magalhães Godinho" (FRANÇA 1997, p. 275). Dois realces, um recalque. Os nomes dos professores nos agradecimentos a lhe ofertar material inacessível, uma escassez - na base do engenho que elabora para a exploração articulada entre problema de pesquisa, documentação e bibliografia. França apresenta como programático algo que, se o for, foi também, e antes, problemático, como se definisse sua posição de maneira favorável ao que ele próprio pôde ser. Para ele, método, senão é tudo, é essencial pois considera a "toilette dos documentos", uma "etapa de erudição apenas". O que avalia ser "história mesmo" é algo que "vem antes ou vem depois. Não se constrói edifícios sem tijolos, mas um monte de tijolos não é um edifício". Somente "quando entra o espírito", "emerge a história" (FRANÇA 1997, p. 133). Quem se dispuser a buscar nas justificativas do que fez e do que deixou de fazer os contornos de um caminho traçado em meio às dificuldades e não às facilidades, ligando-os aos mestres, distanciando-o por vezes de seus amigos, mas não de suas amizades, encontrará, como em Portugal na época da 
Restauração, "a história, mais sentida que pensada, arrastando emocionalmente a[s] inteligência[s]" (FRANÇA 1997, p. 264), na base daquele tirocínio-programa com que abre sua tese: "Tese: uma ideia e um método a serviço da ideia. Para nós foi: a ideia de um método" (FRANÇA 1997, p. 11).

Fernando Novais, saudando-o por ocasião do título de professor emérito, compara a ousadia desta abertura à de Fernand Braudel no Mediterrâneo: "Amo apaixonadamente o Mediterrâneo. Talvez porque, como tantos outros e depois de tantos outros, cheguei até lá vindo das terras frias do norte" (NOVAIS 1994, p. 12). Se acreditarmos em França - "amor contrariado vira teimosia" - a matéria de uma tese encerra desejo insaciável, naturalmente, pelo que não se tem: documentos, mar, cátedra, 1932. Resta ao historiador colher os indícios dele, por meio de sua "intuição".

\section{Considerações finais}

Tomar distância da política e do mercado e estabelecer um conjunto coerente de critérios compartilhados pelos pares-produtores da área: movimento característico dos que se empenham na constituição da autonomia dela. O rechaço ao utilitarismo político e econômico, notável naquele "arrepio" de França, parece se prestar a apagar justamente as transformações políticas e econômicas que se objetivam em seu destino social. A decadência dos estratos tradicionais que relega o drama de se alocar nos setores dominados das elites dirigentes, como educação e cultura, anima esse crescente rechaço aos poderes do dinheiro e da política e se presta à afirmação da autoridade intrínseca ao métier. As linhas de força que se cruzam nas trajetórias dos que em geral a esposam parecem ser similares às que marcaram os caminhos que França percorreu e expressam a transição em curso. Uma década antes, bacharel em Direito, ele talvez fosse professor, como tantos outros profissionais liberais que não lograram se acomodar em seu mercado de trabalho. Uma década depois, talvez licenciado pela FFCL-USP ou outra instituição. O desdém pela justificativa filistina, o antiutilitarismo, sem o qual as áreas da produção simbólica não se autonomizam, nutrem-se dessa vivência, atenuando as marcas de descenso social, ao manifestarem-se em inusitadas ocasiões traduzindo conversões de disposições sociais em tomadas de posição intelectuais. ${ }^{8}$

Convém reconhecer que se algo de interessante este trabalho apresentar, ele deve muito aos pressupostos teóricos e às técnicas de investigação que mobilizou para tanto. É imperativa uma palavra a respeito deles.

Nos últimos anos, têm se multiplicado o interesse pela história da historiografia. Diversas dimensões têm chamado a atenção dos estudiosos: os currículos e as reformas institucionais (RUIZ 2007); os perfis dos professores ligados a definição deles (FERREIRA 2008); as concepções de história subjacentes aos programas de ensino (FREITAS 2006); e, naturalmente, estudos

\footnotetext{
${ }^{8}$ A título de exemplo, atente-se aos termos: "fiz o concurso de catedrático revivendo Portugal na época da Restauração e, com a cátedra ganhei o cobiçado tempo integral, o que me obrigou à monogamia e à despedida daqueles lugares onde lecionando, eu fora feliz talvez sem saber. Ganhava saudades com indenização por tempo de serviço" (FRANÇA 1994, p. 262).
} 
de recorte mais autoral na modulação dos problemas de pesquisa (IUMATTI 2007; NICODEMO 2008; ANHEZINI 2009). Procurando alinhar os esforços aos dos colegas de área, a pesquisa apresentada acima intentou levar a sério o papel desempenhado pelos professores nos "estabelecimentos científicos", como agentes centrais do estabelecimento da hierarquia que os caracteriza (ELIAS 1982, p. 5). Para realizá-lo, testou o rendimento daqueles três passos recomendados por Pierre Bourdieu, adaptando-os ao caso em tela: a análise da posição dos intelectuais/professores junto às classes dirigentes; a análise "da estrutura das relações objetivas entre as posições que os grupos colocados em situação de concorrência pela legitimidade" de arbitrar a respeito de sua atividade; e, por fim, a consideração do habitus, como sistema de disposições socialmente construídas (BOURDIEU 2003, p. 191). Este caminho pressupõe, em detrimento de se operar com uma noção de "inovação historiográfica" estática e destituída de historicidade, a adoção de uma perspectiva relacional, conflitiva e indissociável da produção social das invenções intelectuais. Por esta razão, este tipo de análise não opera estabelecendo uma taxonomia engessada do que caracterize o projeto dos Annales para então julgar a "influência" por exercida pela escola nos historiadores em questão. Como já se sabe que também o projeto dos Annales resulta de operações seletivas da produção social (NOIRIEL 2005, p. 319-339), voltar as energias para medir o índice de fidelidade ou não aos annalistes pareceu um caminho pouco venturoso.

Ademais, vale mencionar que o corpo dos estudantes de Direito/ catedráticos de História com que nos deparamos guarda certo parentesco com o mandarinato alemão em descenso, no final do século XIX, cujas formulações teóricas são indissociáveis dessa situação na estratificação social (RINGER 2000). Em contrapartida, o escopo poderia ser ampliado para o procedimento comparativo, tanto no plano das tradições nacionais, quanto no confronto com outras disciplinas, nos termos em que o fez Wolf Lepenies (1996). O caminho escolhido permitiu auscultar nexos entre dimensões por vezes tratadas de maneira segmentada (recrutamento, currículos, teses, concepções historiográficas); no entanto, trouxe problemas de ordem factual, que se devem explicitar, e de ordem conceitual que convém formular.

No que se refira a dimensões factuais e sociais, ficaram ocultadas as trajetórias femininas. Ao que tudo indica, o interdito a elas não era oriundo de Fernand Braudel. Possivelmente ele estivesse atrelado aos compromissos assumidos com a elite contratante. Vocalizando os valores dela, um expressivo depoimento de João Cruz Costa - que auxiliou o missionário em sua aclimatação no Brasil: "Isso de cátedras com catedráticos femininos não me parece coisa séria" (COSTA 1945). Ademais, a pesquisa sugere que outros atributos, além da oposição mulher/homem, estivessem em jogo nas disputas, por exemplo, a origem "comissionada" ou já capitalizada culturalmente. A investigar.

No que se refira ao impasse conceitual, é notável, a incorporação da linguagem, embora nem sempre dos procedimentos, da sociologia da cultura, dos sistemas escolares e da dominação em alguns estudos de história da historiografia. No entanto, estudos inspirados na "teoria dos campos" de Pierre 
Bourdieu têm mostrado a dificuldade do emprego do conceito para o cenário brasileiro, em função da porosidade dos espaços políticos e intelectuais aos critérios um do outro, traduzidos no intenso intercâmbio entre seus agentes (MICELI 2012, p. 17); a despeito da verificação dos impulsos esporádicos (não estruturais, tampouco estruturantes) por diferenciação das áreas de atividade simbólica (KEINERT 2011, p. 196). Nesse sentido, na historiografia, a figura de Eduardo D'Oliveira França assemelha-se à dos "artífices" da "revolução simbólica por meio da qual os artistas se emancipam da procura burguesa recusando-se a reconhecer outro senhor que não seja a sua arte". Artífices estes que produzem obras cujo efeito consiste em "fazer desaparecer o mercado" e, se possível, o Estado, como árbitros culturais, estabelecendo, enfim o "campo relativamente autônomo" (BOURDIEU 1996, p. 103). Mas isso não significa que consigam. Não basta que um agente espose tal "ponto de vista autônomo" para a verificação da "constituição do campo". França possivelmente seja resultado e agente de uma singular combinação entre modernidade e tradição, e o estudo de seu itinerário propicia, indiretamente, o tratamento "dos impasses subjacentes à constituição da sociedade moderna no Brasil", que estudos recentes têm realizado "por meio da avaliação das elaborações intelectuais, dos dilemas vividos por seus praticantes no esforço de construção de uma experiência culturalmente relevante num meio atravessado por concepções acanhadas e caracterizado por oportunidades limitadas" (ARRUDA 2004, p. 116). Não fosse sacrilégio, encerraria parafraseando-o. Pesquisa: uma hipótese e procedimentos a serviço

100 dela. No presente trabalho, contudo, foi: procedimentos a serviço uma hipótese. À espera de comprovação.

\section{Referências bibliográficas}

ADORNO, S. Os aprendizes do poder. Rio de Janeiro: Paz e Terra, 1988.

ANHEZINI, K. Um metódico à brasileira: a escrita da história de Afonso Taunay. Revista de História, n. 160. São Paulo, junho, 2009.

ARRUDA, M. A. N. Metrópole e cultura. Bauru: Edusc, 2001. . Pensamento brasileiro e sociologia da cultura: questões de interpretação. Tempo social, v. 16, n. 1, jun. 2004.

BORGES, V. P. Memória paulista. São Paulo: Edusp, 1997.

BOURDIEU, P. As regras da arte. Lisboa: Presença, 1996.

. Meditações pascalianas. Rio de Janeiro: Bertrand Brasil, 2001.

. Campo do poder, campo intelectual e habitus de classe. In. Economia das trocas simbólicas. São Paulo: Perspectiva, 2003.

BRAUDEL, F. O ensino de história e suas diretrizes. In. Anuário da Faculdade de Filosofia, Ciências e Letras da Universidade de São Paulo (19341935). São Paulo: Gráfica da Revista dos Tribunaes, 1937.

CAPELATO, M. H. R. O movimento de 1932. São Paulo: Brasiliense, 1982. 
; PRADO, M. L. C. A I'origine de la collaboration universitaire francobrésilienne: une mission française à la Faculté de Philosophic de São Paulo. Préfaces, Paris, 14:100-105, juillet/sep. 1989.

; GLEZER, R.; FERLINI, V. Escola uspiana de história. Estudos avançados, v. 8, n. 22, 1994.

CARDOSO, I. A universidade da comunhão paulista. São Paulo: Cortez, 1982.

COSTA, J. C. Correspondência para Eurípedes Simões de Paula. Centro de Apoio à Pesquisa em História "Sérgio Buarque de Holanda". Projeto Memória. Arquivo João Cruz Costa. São Paulo, 14/08/1944; 28/01/1945. Caixa 23.

DULLES, J. W. F. A Faculdade de Direito de São Paulo e a resistência anti-Vargas, 1938-1945. São Paulo: Edusp, 1984.

ELIAS, N. Scientific establishments. In.: ELIAS, N. MARTINS, E. WHITLEY, R. D. (orgs.). Scientific Establishments and Hierarquies. Dordrecht: D. Rieder, 1982.

A sociedade de corte. Trad. Pedro Sussekind. Rio de Janeiro: Zahar, 2001.

FERREIRA, A. C. A epopeia bandeirante. São Paulo: Unesp, 2002.

FERREIRA, M. M. Perfis e trajetórias dos professores universitários do curso de história no Rio de Janeiro. In: OLIVEIRA, A. J. B. (org.). A universidade

e lugares de memória. Rio de Janeiro: UFRJ, 2008.

FRANÇA, E. O. Portugal na época da restauração. São Paulo: Hucitec, 1997 [1950].

. A teoria geral da história. Considerações a propósito de um livro recente.

Revista de História, n. 7. São Paulo, jul.-set., 1951.

Uma experiência de seminário de utilização de textos. In. PAULA, Eurípedes Simões (org.). Anais do III Simpósio Professores Universitários de História. Franca, 1965.

Planejamento de aulas manuscrito de Eduardo D'Oliveira França.

Centro de Apoio à Pesquisa em História "Sérgio Buarque de Holanda". Projeto Memória. Arquivo Eduardo D’Oliveira França, s/d.

. Prefácio. In: CORRÊA, Anna Maria Martinez. A rebelião de 1924 em

São Paulo. São Paulo: Hucitec, 1976.

Discurso proferido pelo prof. Eduardo D'Oliveira França na cerimônia de outorga do seu título de emérito [1994]. In. Informe: Informativo da Faculdade de Filosofia, Letras e Ciências Humanas da Universidade de São Paulo, n. 14, outubro, 2004. (Edição Especial, 1934/2004).

- Entrevista. Eduardo de Oliveira França: um professor de história.

Estudos Avançados, v. 8, n. 22. São Paulo, set./dez.,1994a. 
Processo 46.1.207.8.7 (Serviço de Expediente da FFLCH-USP).

FREITAS, I. Histórias do ensino de história no Brasil. São Cristóvão: UFS, 2006.

GAGÉ, J. Considerações sobre o curso de História da Civilização. Programa da Cadeira de História da Civilização. Anuário da FFCL-USP, 1937-1938.

GROLA, D. A. A Memória nas Arcadas. São Paulo: Humanitas, 2012.

HILTON, S. A Guerra civil brasileira. Rio de Janeiro: Nova Fronteira, 1982.

IUMATTI, Paulo. Caio Prado Jr.: uma trajetória intelectual. São Paulo: Brasiliense, 2007.

KEINERT, F. C. Cientistas sociais entre ciência e política. Tese de Doutorado, FFLCH-USP, 2011.

KOSELLECK, R. Futuro passado. Rio de Janeiro: Contraponto/Ed. PUC-Rio, 2006.

LEPENIES, W. As três culturas. São Paulo: Edusp, 1996.

LIMONGI, F. Mentores e clientelas da Universidade de São Paulo. In: MICELI, S. (org.). História das Ciências Sociais no Brasil, v. 1. São Paulo: Sumaré, 2001.

LIMA, L. C. Fernand Braudel e o Brasil. São Paulo: Edusp, 2009.

MARTINS, A. L.; BARBUY, H. Arcadas. São Paulo: Alternativa, 1998.

MICELI, S. Intelectuais à brasileira. São Paulo: Companhia das Letras, 2001. Vanguardas em retrocesso. São Paulo: Companhia das Letras, 2012.

NOVAIS, F. A. Apresentação. In. FRANÇA, E. O. Portugal na época da Restauração. São Paulo: Hucitec, 1997.

. Por que história?. Entrevista. D.O. Leitura. São Paulo: Imesp, 2004.

- Discurso de saudação. In. FRANÇA, Eduardo d'Oliveira; NOVAIS, Fernando Antonio; PRADO, Maria Ligia Coelho. A docência como missão e o compromisso com a universidade pública. DSão Paulo: Humanitas, 1997.

NICODEMO, T. L. Urdidura do vivido. São Paulo: Edusp, 2008.

NOIRIEL, G. Naissance du métier d'historien. In. Genèses, n. 1,1990.

Sur la 'crise' de I’histoire. Paris: Gallimard, 2005.

OLIVEIRA, F. V. Fantasmas da tradição. Tese de doutorado. FFLCH-USP, 2012.

PAULA, M. C. R. S. et all. In memoriam de Eurípedes Simões de Paula. São Paulo: FFLCH, 1983.

PEIXOTO, Fernanda. Estrangeiros no Brasil. Dissertação de Mestrado, IFCHUnicamp, 1991. 
PETITJEAN, P. As missões universitárias francesas na criação da Universidade de São Paulo. In: HAMBURGER, A. I. et all. A ciência nas relações Brasil-França (1850-1950). São Paulo: Edusp, 1996.

PRADO, M. L. C. A democracia ilustrada. São Paulo: Ática, 1986.

TRIGO, M. H. B. Os paulistas de quatrocentos anos. São Paulo: Anablume, 2001.

RINGER, F. K. O declínio dos mandarins alemães. São Paulo: Edusp, 2000.

RODRIGUES, L. S. Mestres, discípulos e 'um Seminário'. Tese de Doutorado. FFLCH-USP, 2012.

RUIZ, D. A instituição do ensino universitário de geografia e história na FFCLUSP entre 1934-1956. Agora, v. 13, n. 1, jan./jun., 2007.

SANTOS, M. C.; MOTA, A. São Paulo 1932. São Paulo: Alameda, 2010.

VENANCIO FILHO, A. Das arcadas ao bacharelismo. São Paulo: Perspectiva, 1977. 